$\cdots \quad N-37$

NASA Technical Memorandum 105204

37378

p. 12

\title{
Space Mechanisms Needs for \\ Future NASA Long Duration Space Missions
}

(NASA-TM-105204) SPACE MECHANISMS NEEDS FOR FUTURE NASA LDNG DURATION SPACE MISSIONS (NASA) 12 P CSCL 131 $N 91-30532$

Robert L. Fusaro

Lewis Research Center

Cleveland, Ohio

Prepared for the

Conference on Advanced Space Exploration Initiative Technologies cosponsored by the AIAA, NASA, and OAI Cleveland, Ohio, September 4-6, 1991 
$1=$ 


\title{
SPACE MECHANISMS NEEDS FOR FUTURE NASA LONG DURATION SPACE MISSIONS
}

\author{
Robert L.Fusaro' \\ NASA - Lewis Research Center \\ Cleveland, Ohio
}

\begin{abstract}
Future NASA long duration missions will require high performance, reliable, long-lived mechanical moving systems. In order to develop these systems, high technology components, such as bearings, gears, seals, lubricants, etc., will need to be utilized. There has been concern in the NASA community that the current technology level in these mechanical componenttribology areas may not be adequate to meet the goals of long duration NASA missions such as SEI. To resolve this concern, Lewis Research Center sent a questionnaire to government and industry workers (who have been involved in space mechanism research, design, and implementation) to ask their opinion if the current space mechanisms technology (mechanical components/tribology) is adequate to meet future NASA Missions needs and goals. In addition, a working group consisting of members from each NASA Center, DOD and DOE has been established to investigate the technology status. This paper summarizes the results of the survey and conclusions of the working group.
\end{abstract}

\section{INTRODUCTION}

President Bush has proposed that the United States undertake an ambitious mission of manned and robotic exploration of the solar system. This mission will require high performance, reliable, long-lived mechanical moving systems. In order to ascertain that the systems meet these requirements, the "building blocks" from which these systems are made, such as bearings, gears, seals, lubricants, etc., will have to have the utmost reliability. There has been concern in the NASA community that the current technology level in these areas may not be adequate to meet the goals of this mission or of other long duration missions.

To answer this concern, Lewis Research Center sent a questionnaire to government and industry workers (who have been involved in space mechanism research, design, and implementation) to ask their opinion if the current space mechanisms technology (mechanical components/ tribology) is adequate to meet future NASA Missions needs and goals. Approximately 400 questionnaires were sent and 130 were returned. The responses have been recorded and published in a NASA Technical Memorandum (1). In this publication, the responses were not edited, and were presented in the words of the responder. The names and affiliation of the individuals were not given with the response, but an alphabetized list of those individuals who replied are given at the end of the report.

In addition to the questionnaire, a working group has been established. The group met for the first time at NASA-Lewis Research Center on November 28 \& 29, 1990 to discuss current and future mechanisms needs. The membership of the group includes representatives from all NASA centers as well as representatives from the U.S. Air Force, the Navy and DOE. The purpose of this paper is to summarize the responses to the questionnaire survey, and to present the general findings of the Working Group.

\section{QUESTIONNAIRE RESPONSES}

\section{QUESTIONS 1 AND 2}

The purpose of the first two questions was to obtain the opinion of government and industry people (known to be working in the field) on the current stale-of-the art of space mechanisms technology. The first two questions were essentially the same but were stated differently. The firsi question asked if the state-of-the-art of space mechanisms were adequate to meet future NASA long duration space missions. While the second question asked if there were a need for new or improved space mechanisms technology. A space mechanism was defined as the "building blocks" that make up a mechanism, i.e. the mechanical components or tribology technology that goes into developing a working, moving mechanism. The first question implies if we do not do this technology work, we will not be able to reliably achieve NASA's future space missions. The second question simply asks if new technology is needed. Tables 1 and 2 present a tabulation of the agree and disagree responses to questions 1 and 2, respectively.

The responses were separated into government responses and industry responses to determine if industry and government had a different outlook. It turned out that the agree/disagree responses were very similar for these two groups for both questions 1 and 2 .

There was a greater disparity in the agree/disagree responses between questions 1 and 2, however. More respondees agreed that technology development was needed (98\%) (question 2) than that the technology was inadequate to meet future NASA Missions needs (78\%) (question 1). The probable reason for this difference is that many of the respondees reasoned that American ingenuity could 


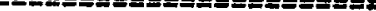

TABLE 1: Response to Questlonnaire Question 1: It appears that the current state-of-the-art of space mechanisms is not adequate to meet new, long duration, future NASA Space Missions such as the space statlon "Freedom", a Lunar Outpost, and unmanned Martlan Missions. Do you agree?

\begin{tabular}{|c|c|c|c|}
\hline RESPONDEE & Agree & Disagree & Not Sure \\
\hline GOVERNMENT & $45(83 \%)$ & $8(15 \%)$ & $1(2 \%)$ \\
\hline INDUSTRY & $53(75 \%)$ & $14(20 \%)$ & $4(5 \%)$ \\
\hline TOTAL & $98(78 \%)$ & $22(18 \%)$ & $5(4 \%)$ \\
\hline
\end{tabular}

Table 2. Response to Questlonmate Question $2:$ is Table 2. Response to Questionnalre Question 2: is there a need for new or Improved space mechanlsms (mechanical components/tribology) technology development?

\begin{tabular}{|c|c|c|c|}
\hline RESPONDEE & Agree & Disagree & Not Sure \\
\hline$N T$ & $51(100 \%)$ & $0(0 \%)$ & $0(0 \%)$ \\
\hline INDUSTRY & $65(96 \%)$ & $3(4 \%)$ & $0(0 \%)$ \\
\hline TOTAL & $119(98 \%)$ & $3(2 \%)$ & $0,0 \%$ \\
\hline
\end{tabular}

overcome any shortfalls in the technology by designing around them. An example is a response by one gentleman: "I designed the steering system, hand controller, and the brakes for the lunar roving vehicle in 1969. If we could do it then, we can do it now. Yet, when the same gentleman answered question 2 he said yes there is a need for new technology.

Questions 1 and 2 also asked the responder to give reasons for their answers. One NASA project Center offered a combined response of several engineers and is a good summary of anticipated needs. The following is their response:

1. Long Lifetimes: It is anticipated that useful operating mechanism lifetimes in excess of 5 years will be required. There is little data available both because few systems have operated for such periods in space and because none of them have been returned to earth for examination. In particular, there is very little NASAinformation available on systems employing bearings. The LDEF experiments may cast some light; however, none of these was operational for the full LDEF mission period. The mechanisms that have operated for long periods have been used in fairly benign applications, i.e. quiet environments, lightly loaded and clean. Also, close attention needs to be paid to the differences between continuously operating, intermittently operating and storage lifetimes.

2. Thermal Cycling: Normal operating ranges for most applications are near room temperature. Although it is likely that space station thermal requirements will be similar to that for most spacecraft, lunar and Martian applications may be quite different with much larger operating extremes and large numbers of quite large thermal excursions.

3. Contamination: All three environments are likely to be worse than for most spacecraft applications. The space station is likely to be a rather busy place and the local environment will suffer from the effects of re-boost, approach by spacecraft, manned excursions and general effluent from a manned structure. The lunar and Martian environments are likely to be especially severe. Large quantities of ambient dust and on Mars, the presence of winds to move them around, provide environments quite different from normal space applications. The lunar dust may be especially bad because of its highly abrasive nature. In addition, the combination of low pressure, temperature and contamination make the environments different enough that extrapolation from earth surface experience is not trivial.

4. Serviceability: The servicing environment for all three applications may be difficult. Although small systems may be serviceable on bringing them into shirtsleeve environments, large systems will either have to be serviceable in situ or disassembled into modules small enough for transport into a workshop. There will also be a large variety of equipment requiring eventual service. It will be very difficult if not impossible to provide a comprehensive set of spares, manuals and trained personnel. Particular attention will have to be paid to redundancy to allow for delaying repairs, self diagnostic systems, conmonality of parts and simplified servicing procedures. On the moon and Mars, maintenance requirements are likely to be high and probably cannot be efficiently met only by replacement of parts.

5. Radiation Resistance: Long lifetimes and operation outside the umbrella of the Earth's magnetic field will require materials and parts with better resistance to radiation degradation than those commonly used today. In addition, more information will be required with respect to operational problems associated with high radiation environments, e.g. single event upsets.

6. Addressing all of the above concerns: Will require a long term technology development program. Because of the significance of the lifetime concems, early initiation of the program is important to allow adequate time to perform life tests. Manrated hardware, especially safety critical hardware, will need to be highly reliable. Because of the times and distances involved and the high cost of replacing hardware, every effort should be made to provide the highest degree of initial reliability. Providing only large degrees of redundancy will be costly, heavy and may not provide the reliability required.

The following are some additional interesting responses to questions $I$ and 2 . For a complete list of the responses see reference 1 . 
- Mechanisms need to have the same focus as structures, i.e. viewed as a discipline. Far too much reinvention of the wheel goes on at NASA.

- In discussions during reviews of proposals for space science missions at NASA Langley by the Langley Space Payload Evaluation Committee, it was generally agreed that there is no basis for vigorous design of mechanisms for long life. What is done currently is to design for 3-5 years life, add some margin in the design, and hope that the mechanism functions for the needed lifetime. This process surely is not acceptable of the long term.

- Specifically, the technology is not adequate for high duty cycle precision motion devices. Bearing design for these applications is still more of an art than a science. New lubricants and materials (ion implantation surfaces, etc.) are available but have not been adequately studied to know what is best for an application. Magnetic suspensions may be necessary for particularly long-lived applications, but then power and electronic reliability problems are substituted for reliability problems. If nothing else, we need better comprehensive life test data on mechanism components.

-- I believe that many past and current NASA Missions have been compromised by having to use "state-of-theart" mechanisms rather than developing enabling technology as part of the pre-project activities. I have seen project guidelines that state that no new technology development will be funded by the project. The result of this posture is compromises in increased weight, power, schedule and decrease in reliability.

-- Long duration reliability under severe environmental conditions is beyond current state-of-the-art.

-- Tribology data used for space mechanism design is difficult if not impossible to obtain and if available, is either not applicable or extremely outdated (Apollo Era). Many company libraries no longer carry documents over 20 years old, however articles published today regarding space mechanisms are so highly specialized as to be of no practical use.

- Yes, new technology is needed. Especially as it relates to mechanisms for instruments and spacecraft that must operate under cryogenic temperatures. Few mechanisms can meet the performance and life specifications of missions such as the proposed Space Infrared Telescope Facility (SIRTF)

- Mechanisms have to be developed as part of the overall system, too often the requirements are component rather than system oriented. For a 30 year life, mechanisms have to be totally redundant, autonomous in operation and totally fail safe. Bearings and devices requiring lubrication need methods to be developed that accurately monitor their health both autonomously and interactively to ensure that lubricant supply is maintained.

-- Much of the existing data does not address mechanism life beyond 5 years. Hostile environmental effects have not been incorporated with existing data. A central library accessible to the space industry is mandatory

- In general, the contractors we deal with are hesitant to reveal the best solution to a problem because it was developed for another customer. That customer may be DOD. The advancement of technology and enhancement of our scientific awareness is being hampered by dollars and politics.

\section{QUESTION 3}

The extent of NASA's current space mechanisms (mechanical components/tribology) technology program is $\$ 60 \mathrm{~K}$ at LeRC directed towards fundamental friction and wear studies. During the Apollo years, there was an extensive program both in mechanical components and lubrication technology at LeRC. If a new program were to be initiated in this area, it would be desirable to ascertain its value as perceived by individuals working in diverse areas of space mechanism design and in various program/project areas. Thus, the third question was: What would be the benefit of a coordinated space mechanisms technology program? How would you benefit from such a program?

The responses fell into seven major categories. These were further divided into subcategories. Table 3 presents a tabulation of the responses received for this question and how many individuals gave that response. The largest number of responses fell into the category of Improved Knowledge (72). This was followed by Technology Improvements (40), Better Use of Funds (39), Improved Communications (25), New Products (15), Standards (6), and Organizational Improvements (1). There were 8 negative comments.

Table 3: Response to Question number 3: What would be the benefit of a coordinated space mechanlsms technology program?

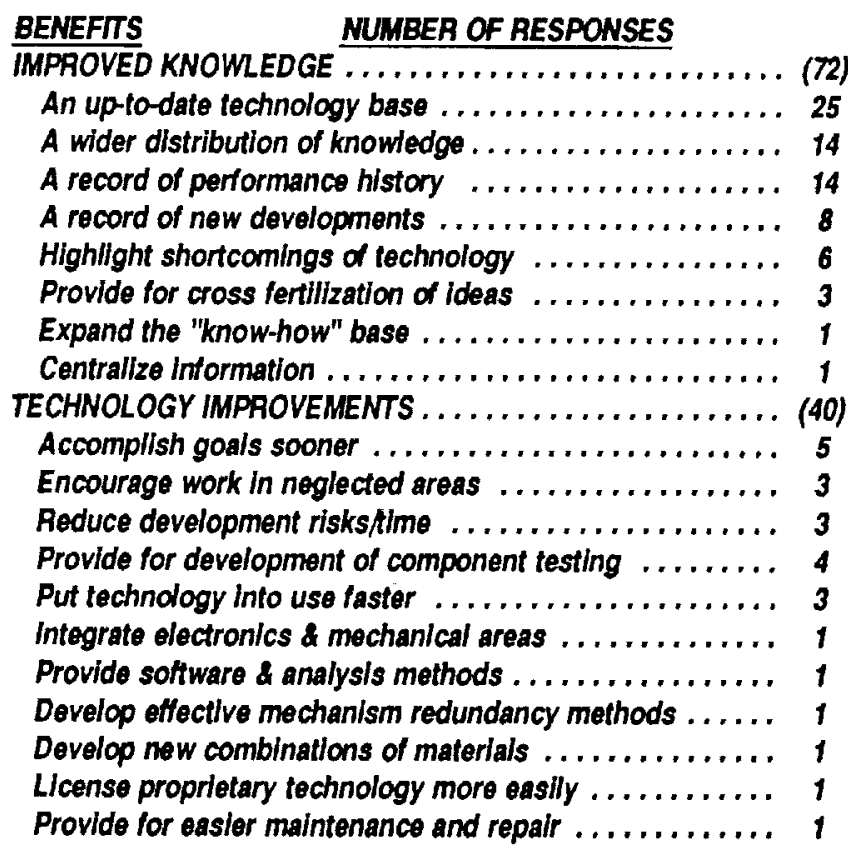




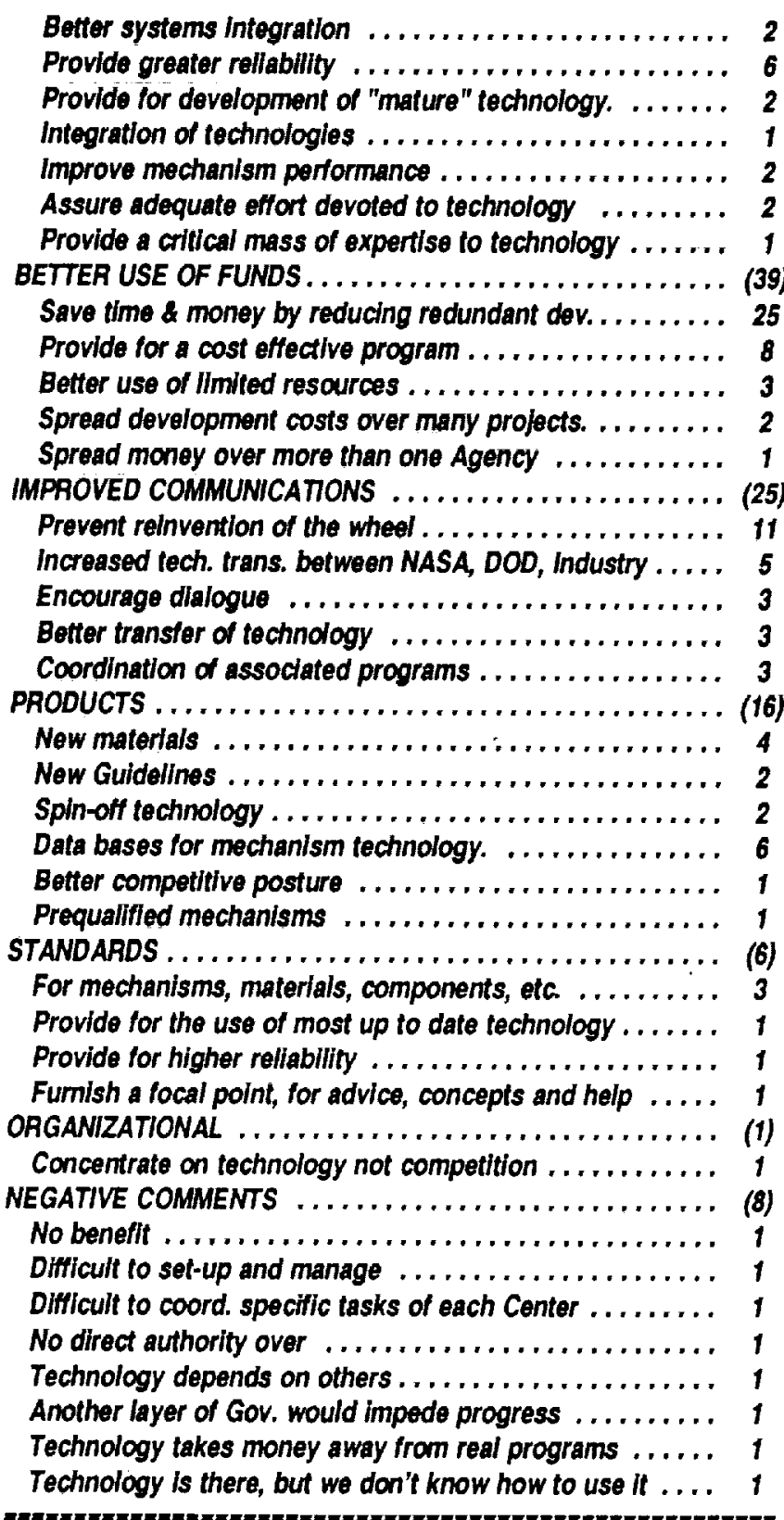

The following are some interesting responses to this question. For a complete list of the responses see ref. 1.

- There is insufficient sharing of knowledge between NASA centers. It is likely that many costs could be avoided if there were better knowledge of the work being done across NASA and the DOD. As new technology is developed to meet the needs of the long term occupation of the solar system it will be especially important that the information is disseminated as widely as possible. If this is not done, the pace of development will be slowed and the "wheel" will be re-invented

- The principal benefit would be the establishment of a much-needed technology data base, the need for which is apparent to design engineers who are asked to execute long-life designs.

- One program cannot necessarily do everything and a well coordinated effort could build on the strengths and successes of the other efforts. Also, coordinated efforts will allow emphasis to be placed on several different mechanisms. I firmly believe that great benefits come from coordinated programs.

-- It has been my experience that every company does its own research quite frequently duplicating the effort of other companies. Common research and data basing could eliminate this and reduce overall costs.

- Because space mechanisms are so unique, so undeveloped, and in such small demand there is not enough private R\&D. Our experimentation is driven primarily by market analysis. Breakthrough technologies are seldom found in chasing existing markets, they are offshoots of other work.

- The benefit would be training for new (and used) engineers; a database of materials, lubricants, and components (including there applicability); standards for mechanisms dynamics; software and analysis methods; and cross training in electronics and mechanical systems.

- A coordinated program would eliminate duplication and provide the most effective means for technology dissemination.

- It could provide data on life tested components that individual projects don't have the time or money to conduct.

- A program consisting of tests to improve life of mechanisms' components and distributing this information to mechanism designers would be beneficial. One problem now is knowing what developments have been made already and always having to start from the beginning because information on mechanism development is not well circulated.

- The biggest benefit would be the spinoffs to more mundane, earth-based systems. This was demonstrated repeatedly during the 50's and 60's when space exploration was more popular than it has been recently. A technical capability invariably comes up with more useful general solutions than a mind which looks only within a narrow constrained area.

\section{QUESTION 4}

Currently at NASA there is no infrastructure to deal with developing new mechanism technology or for providing guidance to projects. The fourth question asked if there were an infrastructure created what should be its functions. Table 4 presents yes/no/undecided responses to a number of different functions this infrastructure could perform.

All the infrastructure functions mentioned received very positive responses. The number one positive response was that an infrastructure should provide maintenance of a data base on capabilities and solutions (118). The lowest response was for developing standards for U.S. industry use (76). The apparent reason for the lower positive response to this question was that some individuals do not want strict standards to be imposed on them. Guidelines probably would have been a better word than standards. 
Table 4: Response to Questionnaire Question 4: Do you teel there Is a need for NASA to establish a Space Mechanisms Technology Intrastructure in order to:

\begin{tabular}{|c|c|c|}
\hline \multirow{3}{*}{$\begin{array}{l}\text { (1) Coordinate new technology } \\
\text { development. } \ldots \ldots \ldots \ldots \ldots \ldots \ldots \ldots 113 \\
\text { (2) Develop standards for U.S. }\end{array}$} & \multirow{3}{*}{$\frac{\text { NO }}{10}$} & $?$ \\
\hline & & \\
\hline & & 1 \\
\hline $\begin{array}{l}\text { Industry use. } \ldots \ldots \ldots \ldots \ldots \ldots \ldots \ldots 76 \\
\text { (3) Furnish consultancy and }\end{array}$ & 39 & 9 \\
\hline $\begin{array}{l}\text { advisory services. ...............96 } \\
\text { (4) Maintain a data base on }\end{array}$ & 19 & 9 \\
\hline $\begin{array}{l}\text { capabilitles and solutions. } \ldots \ldots \ldots \ldots 118 \\
\text { (5) Maintain festing facilities }\end{array}$ & 3 & 3 \\
\hline $\begin{array}{l}\text { Ior U.S. space interests. . . . . . . . } 106 \\
\text { (6) Faciltate the transfer of space }\end{array}$ & 10 & 8 \\
\hline $\begin{array}{l}\text { technology. . . . . . . . . . . . . . . } 117 \\
\text { (7) Encourage crosstalk between }\end{array}$ & 4 & 0 \\
\hline $\begin{array}{l}\text { government and Industry } \ldots \ldots \ldots \ldots \ldots 113 \\
\text { (8) Insure Coordination of NASA }\end{array}$ & 6 & 5 \\
\hline $\operatorname{sarch} \ldots \ldots \ldots \ldots \ldots \ldots 115$ & 6 & 3 \\
\hline
\end{tabular}

Question 4 also asked what sort of tasks should be added to a space mechanisms technology infrastructure. Table 5 presents a list of those areas that were mentioned.

Table 5: Responses to Question number 4. What sort of tasks should be added to a Space Mechanisms Technology Intrastructure?

\section{RESPONSES}

- Academic interaction

-- Methods of educating U.S. Industry on technology development

-. Testing and evaluation of "Brand Name Products"

- DOE National Labs should be included in coord. effort

- Develop science base

- Develop new materials that are light and strong

- Define requirements for specific mechanisms

-- Develop solutions

-- Catalogue past and ongoing space mechanisms/tribology technology developments

- Coordinate requirements of mechanical noods

-. Adrocate additional testing facilities

- Develop analytical tools for mechanisms

- Simplity mechanisms dev., documentation and process control

-- Develop an effective communications sys. for govnmt. customers

The following are some responses to question 4 . For a complete list see reference 1 :

-- Coordinate new technology development: Yes, however, this program need not be extremely expensive or all encompassing. An appropriate approach would be a NASA wide equivalent to the Director's Discretionary Fund with encouragement of governmen $V$ contractor cooperation. In addition, proposals for small scale very advanced work in specific areas could be solicited with a winnowing process at successive stages to select the most promising and fund them for further development. Cooperative development efforts for new technology between many projects should be encouraged. Large scale development should be done in the context of a specific application.

- Develop standards for U.S. Industry: No, this is an activity best transferred to NIST or one of the professional societies. NASA is likely to be best served by identifying a need and funding these activities in another organization that already has the expertise and the charter.

- Furnish consultancy and advisory service: Yes, but this function is likely to be best served by establishing a data base and sponsoring symposia. It may be appropriate to create NASA Fellows whose charter is to do fundamental investigations and developments and serve in the consultancy and advisory role.

- Maintain a comprehensive data base: Yes, this activity is much needed. At present, the generation of engineers that powered the moon program and much of NASA's early success has retired or is nearing retirement. Access to much of the technical heritage of the agency and its contractors is limited by there not being a central "card catalog" of the information that exists in these peoples' heads and file cabinets. This should be the highest priority of the items mentioned. It could be funded through NIST or one of the existing technical database services.

- Maintain adequate testing facilities for U.S. space interests: Yes; the type of environmental testing needed is likely to require facilities beyond the present capabilities and beyond those feasible for one center, program, or project to set-up by itself. Existence of an agency test facility, especially if the services were provided free for appropriate test programs would substantially expedite the initial stages of new technology development. Such facilities could be most cheaply created by augmentation of existing facilities at NASA centers coupled with an appropriate budget for test support.

- Facilitate the transfer of space technology: Yes, this function can be met through the data base discussed above, the existing tech brief system and the sponsorship of symposia. A large benefit could be obtained if travel funds could be made available for attendance of these symposia by more NASA engineers. At present, attendance is sharply restricted by the limited availability of administratively controlled travel funds.

- Ensure coordination of NASA and DOD research: Yes. This is likely to be the most difficult area of all due to the veil of secrecy likely to descend on very advanced technology. NASA's and DOD's needs will overlap substantially and the cooperation is well worth pursuing. substantial benefits can be realized in this area through the data base development. Cooperative efforts are likely to follow spontaneously if the different groups know what the others are doing. 
- As a leadership agency for civil space, NASA not only has an opportunity of establish a space mechanisms infrastructure, but has been remiss in ignoring this critical element of technology in its program to date. It has been left to each project to fund any mechanisms development required to meet missions objectives. Each project focuses on its immediate needs with not attention paid to future requirements. Limited dissemination of technology occurs, and we reinvent at least a partial "wheel" each time.

- Not only could NASA "standardize" the industry somewhat, it could provide coordination of govt Sponsored R\&D to meet critical performance issues. Between all our govt customers, there seems to be absolutely no crosstalk in the mechanisms area.

- The old timers have left or are retiring rapidly. It has become evident to me that the new engineers are not aware of the pit-falls. Materials and lubrication questions come up regularly. . The industry needs guidelines based on a variety of operating parameters.

\section{QUESTION 5}

Generally no new technology gets integrated into spacecraft unless there is proof that it will perform as desired. The problem is, other than actually using it in a spacecraft, how does one qualify a new mechanism for use in space. Question 5 asks, "what kind of space qualification techniques need to be developed." Table 6 presents a tabulation of the responses to that question.

Table 6: Response to Question number 5: What kind of space qualification fechniques need to be developed?

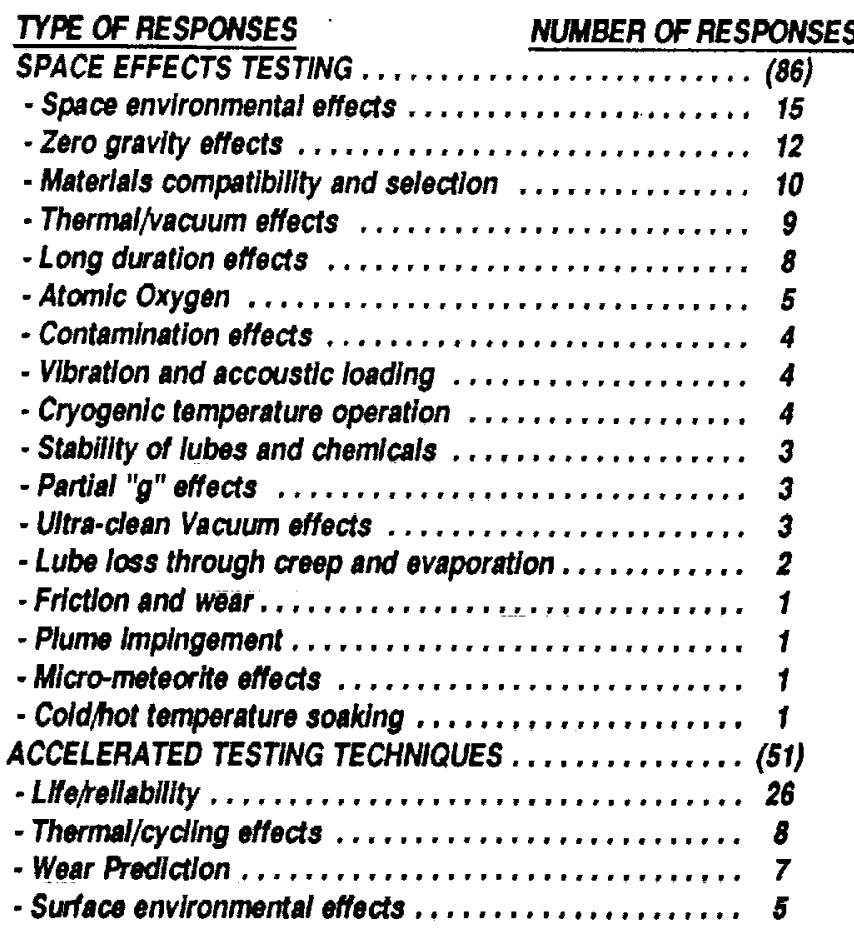

- Materials durabillty ..................... 5

COMPONENT TESTING . . . . . . . . . . . . . . (26)

- Lubricants .............................. 12

- Rolling element bearings . . . . . . . . . . . . . . 7

- Seals .............................. 3

- Dither motion . ............................ 2

- Gimbals ............................ 1

- Sllding motion ........................ 1

ANALYSIS AND MODELING ................. (13)

- Analytical methodology 4 data base ............. 2

- Theoretical analysis ....................... 1

- Advanced modeling methods ................... 1

- Computer simulation ........................ 1

The responses fell into 4 major categories. The category receiving the greatest number of responses was Space Effects Testing (86). This was followed by Accelerated Testing Techniques (51), Component Testing (26), and Analysis and Modeling (13). Even though space effects testing had the largest overall category response, the subcategory area that had the greatest response was Life/Reliability testing under Accelerated Testing Techniques. Some sub-category areas are listed in both the categories of Accelerated Testing Techniques and Space Effects Testing. The reason for this is to distinguish between parameter effects testing and accelerated testing.

The following are some responses to question number 4 .

For a complete list see reference I:

- Accelerated testing for lifetimes of 30 years poses an extremely difficult problem. Even when only $5-10$ years are involved, one never really knows whether the speeding up of the test cycles affected the result, either positively or negatively. Basically, some long, 10-year tests are needed -probably at the real-time rate. Then we'll need an ability to extrapolate to 20 or 30 years.

- The whole area of space environmental testing needs development. Fundamental research needs to be done to allow accelerated thermal cycle life testing to be performed. Computer simulation and modeling need to be exploited and integrated with real time testing to allow reliable predictions of system performance including identification of failure susceptibility, performance degradation, etc.

-- Having been involved with many space satellites and NASA-hardware I feel qualification standards and guidelines should be established. I have found that different agencies or companies seem to have varied guidelines on qualification standards. Such as cleanliness levels, materials used, and different testing techniques.

- We currently don't do any qualification testing of mechanisms which subjects them to specific space environments which could be damaging, i.e., atomic oxygen, ultra-violet degradation, micro-meteorite bombardment, etc. These space unique environments should be mimicked in qualification test programs. 


\section{QUESTION 6}

In question 6 , the responders were asked to list what they thought were the current and future space mechanisnis needs. Table 7 lists those needs along with the number of responders stating each need. Forty different component area needs were stated. The number I need appears to be for liquid lubricants, 34 responders gave this as a need. Mechanisms materials was second with 27 , followed by high speed bearings 24 , solid lubricants 23 , etc.

Table 7: Response to question number 6: What are some current or anticipated space mechanisms needs?

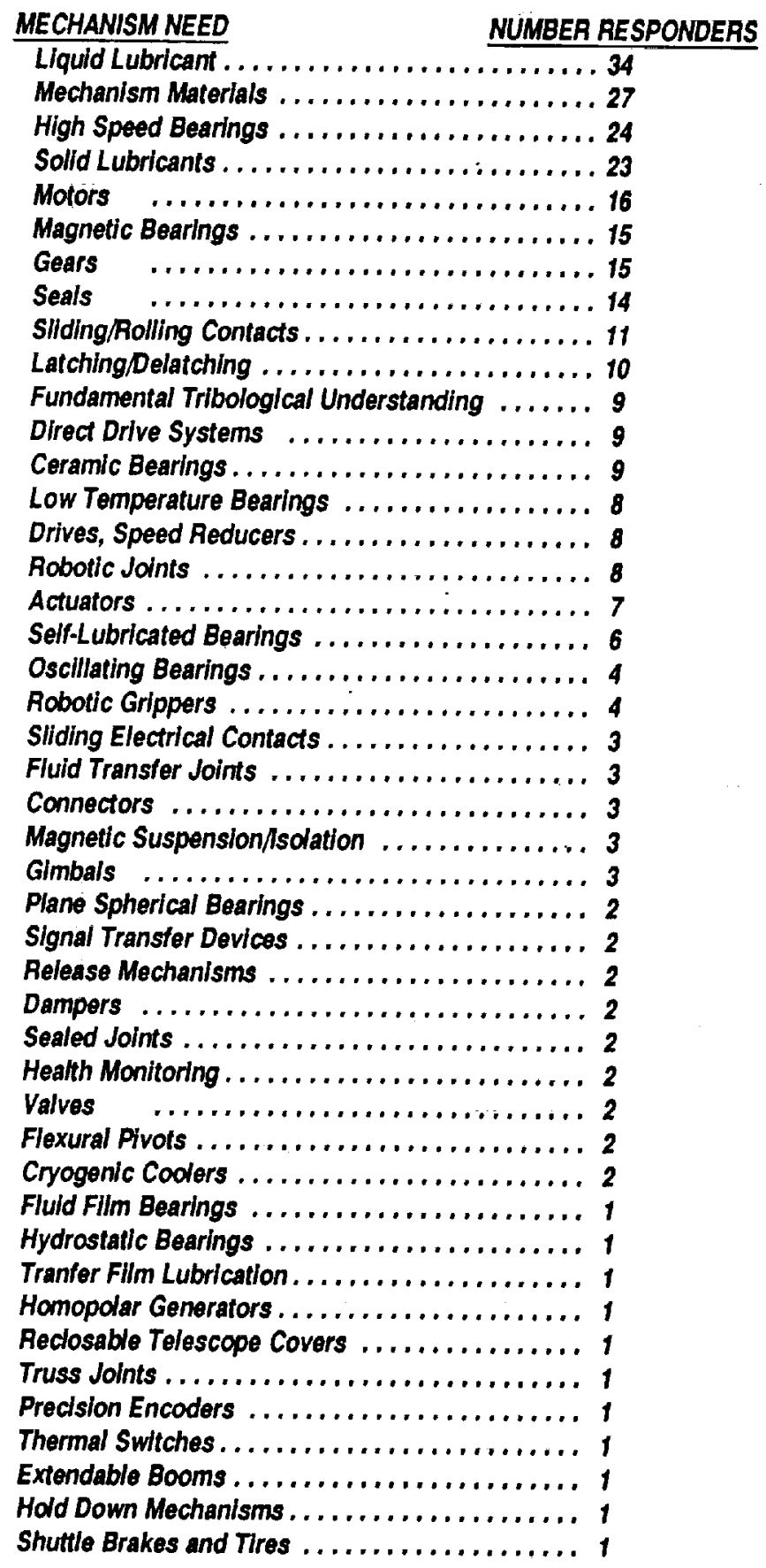

Launch Interface Hoses/connectors . . . . . . . . . . . 1

Silp Rings . . . . . . . . . . . . . . . . . . . . 1

Pipe Connectors ..................... 1

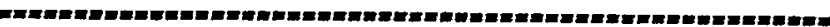

The following are some individual responses to question number 6 . For a complete list see reference 1:

-- The following will be needed for an SEI mission:

(A) Fixed Scientific Equipment: (1) Large telescopesgimbals and motors; smaller actuators for smaller mirrors. (2) Observatory domes, windows and ports. (3) Facility helium and nitrogen liquefiers and liquid handling systems. (4) Mechanical refrigerators for site cooling. (B) Habitat, Construction, Drilling and Maintenance and Heavy Transport: (1) Drilling and coring for heat pumps, water, etc. (2) Heavy excavation equipment for raw material excavation and handling. (3) Pumps for heating and cooling equipment (must preclude refrigerants leaking into breathing spaces). (4) Airlocks and vacuum pumps. (5) Antenna Pointing. (6) Waste and vent valving. (7) Heavy and bulky material transport systems. (8) Power generation and storage (motor/generators for high voltage AC power, pumps and compressors for electrolyzed $\mathrm{H} 2$ and 02 storage). (9) Antennae and sensitive structure deployment and turning. (10) Inflatable structures for temporary and semipermanent shelter (for both men and equipment). (11) Fully telerobotic servicing and assembly for dangerous environments such as long duration exposure during solar storms, long trips on the lunar and Martian surface not feasible with the overhead of life support systems. (12) Heavy transport for construction and movement of major equipment. (13) Lunar to orbit launch facilities such as an electromagnetic rail gun. (C) Exploration and Mobile Science: (1) Light weight rover (all terrain, man-rated). (2) Long range, light weight rover (nonmanrated, telerobotic with gripping). (3) Portable drilling and coring. (4) Umbilical connects/disconnects for refueling and connecting vehicles. (D) Critical Technologies: (1) Seals and sealants (O-rings, gaskets, suit and tent materials). (2)Bearings (lubrication, contamination sealing). (3) Motors and geartrains (lubricants, contamination sealing). (4) Magnetic or other non-contacting bearings for sealable long lifetime equipment. (5) Abrasion, radiation darkening and contamination resistant optical surfaces for sensors, viewports and solar cells. (6) Further development in composite materials for both mechanisms and structures. (7) Need further development in lightweight, high strength alloys such as advanced aluminum alloys (i.e. Al-Li). (8) Robotic servicing and unmanned exploration augmentation, particularly fully telerobotic operation. (9) Bio-mechanisms- human life support facilities will require especially high degrees of reliability, serviceability and diagnostic capability. (10) Wide speed range direct drive systems minimizing the use of gears. (11) Power generation. The key to many 
technologies is the availability of power. This may be met with ruggedized, light weight, efficient solar cells and the technology to produce then on the moon, selonothermal generation, surface/subsoil thermopiles, light/dark zone thermopiles or nuclear power. How much power will be available and when it will be available during the exploration and habitation may be both technology selecting and rate determining. Any or all of these activities are likely to require mechanisms development.

- Development of long life (5-10 years), vibration free $(<0.1 \mathrm{~N})$, cryogenic coolers $(30 \mathrm{~K}, 40 \mathrm{~K}$ and $55 \mathrm{~K}$ each with 2 or more watts heat lift) is required. Accurate, light-weight low temperature $(<55 \mathrm{~K})$ thermal switches are needed. Development of technologies to make and test advanced IR sensors with new materials capable of operation in the very long range $I R$ is required. Laser technologies are in dire need of having their efficiencies improved as well as how to accommodate the power and thermal problems encountered. Most laser systems are too heavy for practical space flight and require far too much power. Highly accurate spacecraft pointing systems are needed, inexpensive and affordable pointing systems for instruments are needed. High volume data slorage and data transfer mechanisms are required $(300$ megabyte to 500 megabyte recording and playback, random access) to name just a few. Some other space mechanisms needs are an adequately functioning very large (4 ft to $20 \mathrm{ft}$ diameter) rotating joint which can safely transfer fluids and gases simultaneously without leaking or losing efficiency, thermal subsystems which can be self adjusting that will cover and range from very close to the sun all the way out to and beyond Mars and provide a livable environment for astronauts, improved docking mechanisms, telerobotic mechanisms for maintenance and repair activities for long term missions, improved astronaut personal propulsion systems accompanied by a compact guidance/orientation system, and improved space suits with increased mobility, better thermal control and more flexibility.

- (1) Valves, disconnects, regulators capable of operating continuously or intermittently for more than five years without failure and requiring no maintenance or lubrication. (2) Actuators for valves and mechanical components that can be operated electrically as well as manually by an astronaut and/or end effector. (3) A quick leak repair kit for fluid transfer lines. (4) $\Lambda$ manually driven electrical power supply capable of recharging portable electrical power tool and appliance battery packs. (5) Manually driven mechanic power/transmission device. (6) Jam proof latches, actuators, gears fasteners designs requiring no maintenance or lubrication. (7) structural shell leakage repair devices.

- Improved lubrication for controlled moment gyro (CMG) ball bearings - perhaps hard coatings. Improved lubrication for harmonic drive gears and bearings.
--(1) Development of self-lubricating solid materials with structural strength of long-lasting coatings to meet tribology requirements. (2) development of boundary lubrication technology for space applications. (3) Development of fluid-film (liquid or gas) lubrication technology and related sealing technology for spaceapplications. (4) tribology is a link or an aspect of the over-all system. Some tribology problems can be solved through novel designs of mechanisms. I see the general need for developing a new design philosophy for space applications.

\section{SPACE MECHANISMS WORKING GROUP FINDINGS}

A space mechanisms working group has been established and met at NASA-Lewis Research Center on November 28 \& 29, 1990 to discuss current and future mechanisms needs. The membership included representatives from all NASA centers as well as representatives from the U.S. Air Force, the Navy and DOE. The conclusions arrived at the workshop were as follows:

\section{SIGNIFICANT PROGRAMMATIC ISSUES}

1. NASA faces imminent space mechanisms failures if space mechanisms technology issues are not better addressed.

2. Future long duration missions will be jeopardized if the technology base is not improved.

3. There is a lack of adequate NASA facilities for accelerated testing, life testing, environmental resting and functional testing.

4. NASA expertise is retiring, new people are not being trained, creating a loss of corporate memory.

5. There is no one at NASA Headquarters to deal with mechanisms technology, mechanisms needs recognition as a discipline.

6. A "place" is need to go with Questions!

\section{SIGNIFICANT TECHNOLOGY ISSUES}

1. Mechanisms/tribology technology data base is outdated (20+ years old).

2. There are no real guidelines, handbooks, or standards available for designers.

3. There is an inadequate understanding of mechanisms failure modes.

4. Accelerated testing for a "30 year life" is an unknown.

5. Potential detrimental environmental effects difficulties may exist which are currently unknown.

6. Storage of mechanisms prior to launch is a significant problem.

7. Operation at lower cryogenic temperatures $\left(2.6^{\circ} \mathrm{K}\right.$ versus $77^{\circ} \mathrm{K}$ ) posses a challenge.

8. Serviceability and maintenance of mechanisms not being considered.

9. Vibration isolation will be an important consideration for large platforms and for microgravity science work and 
is not being adequately addressed.

\section{TECHNOLOGY IMPLEMENTATION NEEDS}

1. A mechanism design rules and guidelines manual.

2. Validated accelerated test methods.

- For harsh environments.

- For critical components.

3. A catalog of historical mechanism/tribological problems and solutions from previous NASA missions.

4. Petition Aerospace Mechanisms Symposium to present more papers on space mechanisms/tribology technology.

5. Form splinter working groups on specific problem areas.

\section{SPACE MECHANISMS INFRASTRUCTURE ISSUE}

The working group also addressed the issue of the need for establishing a space mechanisms infrastructure. All were in agreement that an infrastructure was needed, but the organizational structure is uncertain. The group felt it should include: (1) a full time program coordinator, (2) a Headquarters sponsor (with \$), (3) a permanent working group to identify problems, solutions, sources of money, (4) sub-working groups to address focussed technology areas, (5) formal cooperation between NASA Headquarters codes $R, S$, and $M$ to establish common goals, and (6) that it should support the space industry like NASA supports the aeronautics industry. A suggestion was made that it could be supported by taxing projects.

\section{WORKING GROUP'S FUTURE PLANS}

The working group is continuing to meet through regularly scheduled Video Conferences. Currently the primary project of the group is to catalog the historical mechanisms/tribological problems and solutions from previous NASA missions. The group is also planning to conduct an industry wide workshop on space mechanisms.

\section{TECHNOLOGY OBSERVATION}

One of the main hindrances for the initiation of new technology work in space mechanisms has been that mechanical components and tribology are somewhat taken for granted, since for most Earth-based conditions, the technology is adequate to meet most requirements. But in reality, the lubrication of mechanical components is more of an art than it is a science, especially when boundary lubrication is involved. Many Earth-based problems have been solved through an Edisonian approach (trial and error). In space, there are different parameters and requirements than there are on Earth and the interaction of these parameters have not been evaluated. Thus, we do not really know if the technology that has been successful on Earth will be successful in Space.

Friction, wear and lubrication are extremely systems dependent. Change one operating parameter (speed, load, atmosphere, contact geometry, etc.), and the part may fail catastrophically! For example, most designers are unaware of the important role that surface oxide films play in the lubrication process. In vacuum, where oxide films can not be reformed once they are wom away, a part may fail catastrophically. Thus even though the bearing material worked exceptionally well on Earth, in space it may be unsuitable due to the lack of surface oxidation. Thus there is a major need to develop mechanisms technology specifically for particular space applications.

\section{SUMMARY}

NASA has been experiencing a number of disconcerting spacecraft anomalies the last few years. The conclusion that one draws from the results of the questionnaire and the space mechanisms workshop is that inadequate technology in the area of mechanical components and lubrication (tribology) may be a contributing factor. Mechanical components and lubrication systems are the building blocks from which moving mechanical devices are made. If we do not have adequate building blocks, the whole structure will be weak! There is a lot of new technology available in mechanical component'tribology area, however it has not been evaluated or qualified for use under the specific application conditions. Qualification methods need to be established to get newly developed rechnology flying.

To address current and future space mechanism needs, a working group has been formed consisting of members from all NASA Centers and members from the DOD and DOE. The consensus of the group is that technology is deficient in the space mechanisms area and that work should be initiated immediately to advance the state-of-theart and to establish a catalog of historical mechanisms/ tribology problems and solutions from previous missions.

\section{REFERENCES}

1. Fusaro, Robert L., Government/ndustry Response to Questionnaire on Space Mechanisms/Tribology Technology Needs. NASA TM 104358, May 1991. 
Public reporting burden for this colfection of information ls estimated to average 1 hour per response, including the time for revlewing instructions, searching existing data sources gathering and maintaining the data needed, and completing and reviewing the collection of iniormation. Send comments regarding this burden estimale or any other aspect of this collection of information, Including suggestions for reducing this burden, to Washinglon Headquarters Services, Directorate lor information Operations and Peports, 1215 Jefferson Davis Highway, Suite 1204, Arlington, VA 22202-4302, and to the Otfice of Management and Budget, Papenwork Peduction Project (0704-018B), Washinglon, DC 20503.

\begin{tabular}{|l|l|l}
\hline 1. AGENCY USE ONLY (Leave blank) & $\begin{array}{c}\text { 2. REPORT DATE } \\
\text { September } 1991\end{array}$ & $\begin{array}{r}\text { 3. REPORT TYPE AND DATES COVERED } \\
\text { Technical Memorandum }\end{array}$ \\
\hline
\end{tabular}

4. TITLE AND SUBTITLE

Space Mechanisms Needs for Future NASA Long

Duration Space Missions

\section{FUNDING NUMBERS}

WU - 505- 63-5B

6. AUTHOR(S)

Robert L. Fusaro

\section{PERFORMING ORGANIZATION NAME(S) AND ADDRESS(ES)}

National Aeronautics and Space Administration

Lewis Research Center

Cleveland, Ohio 44135 - 3191
B. PERFORMING ORGANIZATION REPORT NUMBER

E -6507
9. SPONSORING/MONITORING AGENCY NAMES(S) AND ADDRESS(ES)

National Aeronautics and Space Administration

Washington, D.C. 20546-0001
10. SPONSORING/MONITORING AGENCY REPORT NUMBER

NASA TM - 105204

11. SUPPLEMENTARY NOTES

Prepared for the Conference on Advanced Space Exploration Initiative Technologies cosponsored by AIAA, NASA, and OAI, Cleveland, Ohio, September 4 - 6, 1991. Responsible person, Robert L. Fusaro, (216) 433 - 6080.

12a. DISTAIBUTION/AVAILABILITY STATEMENT

Unclassified - Unlimited

Subject Categories 37 and 18 12b. DISTRIBUTION CODE

\section{ABSTRACT (Maximum 200 words)}

Future NASA long duration missions will require high performance, reliable, long-lived mechanical moving systems. In order to develop these systems, high technology components, such as bearings, gears, seals, lubricants, etc., will need to be utilized. There has been concem in the NASA comnunity that the current technology level in these mechanical component/tribology areas may not be adequate to meet the goals of long duration NASA missions such as SEI. To resolve this concern, Lewis Research Center sent a questionnaire to government and industry workers (who have been involved in space mechanism research, design, and implementation) to ask their opinion if the current space mechanisms technology (mechanical components/tribology) is adequate to meet future NASA Missions needs and goals. In addition, a working group consisting of members from each NASA Center, DOD and DOE has been established to investigate the technology status. This paper summarizes the results of the survey and conclusions of the working group. $+\pi \tau$

\section{8UBJECT TEAM8}

Spacecraft components; Bearings; Gears; Seals; Lubricants; Tribology; Ball bearings; Mechanism; Mechanical devices; Vacuum; Space

\section{NUMBER OF PAGES}

10

16. PRICE CODE

$\mathrm{AO} 2$

18. SECURITY CLASSIFICATION
OF THIS PAGE
Unclassified

Unclassified
19. SECURITY CLASSIFICATION OF ABSTRACT Unclassified

